\title{
FRAME SEMANTICS AND VERBS OF MOTION. THE CASE OF ENTER AND GO INTO. A CORPUS-BASED STUDY
}

\author{
Svetlana Nedelcheva*, Mariana Todorova**
}

\begin{abstract}
The article studies the verbs enter and go into in a corpus of technical texts on a comparative basis. We apply the methodology of Frame semantics with the purpose of showing foreign learners of English an indicative characteristic of the language, i.e. the various constructions, in which enter and go into participate, as well as the semantic network of their distinctive meanings. In this research we rely on the usagebased approach and provide evidence for the importance of context in the semantic analysis and frame profiling. The analysis contributes to constructing a theoretically and empirically coherent approach to technical corpus data and investigating its specificities to help students acquire English constructions and use them efficiently and effortlessly in written and spoken communication.
\end{abstract}

Key words: enter vs. go into, Frame semantics, corpus of technical texts, polysemy

\section{Introduction}

This study approaches motion verbs from the perspective of Frame semantics (Fillmore, 1977, 2006, 2007; Fillmore, Atkins, 1992, 1994, 2000), which analyzes situations in terms of frames consisting of participants playing particular roles in events, and lexical items are described in relation to these semantic frames. Frame semantics relies on empirical semantics which emphasizes the continuity between language and experience, and provides a framework for presenting it. In Frame Semantics, a word represents a category of experience. It focuses on the relation of linguistic semantics to encyclopedic knowledge. Basically, one cannot understand the meaning of a single word without having all the essential knowledge that relates to that word.

Frame semantics as an approach developed by Charles J. Fillmore builds up on his earlier theory of case grammar, most directly to case frames. Case frames can be defined as "characterizing a small abstract 'scene' or 'situation', so that to understand the semantic structure of the verb it was necessary to understand the properties of such schematized scenes" (Fillmore, 1982, p. 115). For instance, in order to make sense of the verb to fall in the example "the tree fell on the house" one needs to have sufficient knowledge about trees and gravity. One has

\footnotetext{
* Assoc. Professor PhD at the Department of English Studies, Shumen University, Shumen, Bulgaria, e-mail: s.nedelcheva@shu.bg.

** PhD Candidate at the Department of English Studies, Shumen University, Shumen; EFL lecturer at Technical University of Varna, Bulgaria, e-mail: mariana.tod@gmail.com
} 
to know that trees when detached from their roots are affected by gravity. They can no longer stay erect and fall down and if there is something on their way to the ground it undergoes their weight.

Frame semantics aims at linguistically appropriate generalizations about words related to each other in the environment of the same predicate, without encoding in the sentence the full scope of a speaker's knowledge of events in the world. A semantic frame is a collection of facts that specify "characteristic features, attributes, and functions of a denotatum, and its characteristic interactions with things necessarily or typically associated with it" (Alan, 2001, p. 251). Frames are based on recurring experiences. Following Evans (2006), we assume that meaning is "a constructive process, in which integration of lexical units involves differential access to the conceptual knowledge which lexical entities potentially afford access to" (Evans, 2006, p. 496). Meaning does not belong to linguistic entities as such but it is a dynamic process, a function of their use in linguistic context where a word ensures access to a wide network of encyclopedic knowledge to the participants in the communication process.

Fillmore (2006, p. 378) claims mutual implication in the correlation between frames, construals and lexical items in which the frame is "the structured way in which the scene is presented or remembered, [and] we can say that the frame structures the word-meanings, and that the word 'evokes' the frame". The Frame semantic representation allows us to express clearly the relation of the senses to each other and to other lexical items. Although originally Frame semantics was only applied to lexemes, now it is used as an approach to grammatical constructions and other larger and more complex linguistic units, which integrates it to a certain degree into construction grammar. A complete description of these verbs must also include information about their grammatical properties and the various syntactic patterns in which they occur.

Frames may be of two broad semantic types: event or state. Roles generally have semantic types, and these types are inherited along with the role. If an event frame has to be divided into sub-events, these are termed scenes in the frame. Scenes, like frames, have types and may use or inherit from other frames, in addition to any inheritance of the frame as a whole. Goldberg's (2010, p. 40) definition points out the internal constituency of verbal frames:

a. A word sense's semantic frame (what the word 'means' or 'evokes') = profile + background frame

b. A word sense's profile: what the word designates, asserts

c. A word sense's background frame: what the word takes for granted, presupposes.

The speaker profiles one element of the frame. Each sense of a lexical item is associated with a separate lexical concept which, under local contextual influences, can be further modified. 


\section{Corpus evidence}

\subsection{Method and Data Collection Procedure}

The study is based on a corpus of technical texts collected ad hoc. The content of nineteen books in the subject field of marine engineering, naval architecture and ship handling (a total of 23626 words) was inserted into Simple Concordance Program 4.09*. We used the software to analyze the imported texts and create a wordlist exhibiting the usage frequency for each extracted word. Among the motion verbs enter turned to be one of the most frequently found in the corpus. However, there is no option in the software for lemma search. Therefore, all possible forms of enter and go into, such as enters, entered, entering, goes, went, gone, going were applied as keywords to the search field. We obtained as results 224 hits for the lemma enter, which showed that the form entering is the most frequently used (36\%) compared to the other three enters $(29 \%)$, enter $(25 \%)$ and entered (10\%). For the lemma go we received 114 hits. Again the ing-form appeared as the most frequent one (37\%), go following with $35 \%$. The share of other three forms, goes, went, gone, is $21 \%, 5 \%$ and $2 \%$, respectively. Only 9 instances of them belong to go into.

The aim of the article is to present the different frames enter and go into construct and to define the frame elements surrounding them in their various uses. Next, we try to build the semantic network of the verbs enter and go into in technical texts.

\subsection{Instruments}

We chose to address the issue starting with the complete inventory of the frame patterns associated with the respective verbs. The process of building such inventories is already in progress under various research projects developing on-line lexical databases, which include valency information, such as FrameNet (Fillmore, Baker, 2010; Ruppenhoferet al., 2010), the Erlangen Valency Pattern Bank (Herbst et al., 2004), and WordNet (Fellbaum, 1998)**. These lexical databases apply both lexical and phrasal approaches to arrive at a more adequate empirical representation of predicate argument structures and valency information. However, as this study is defined as a corpus-based one, we start analyzing the examples excerpted especially for the purposes of the present research and then compare the results to the constructions enlisted in

\footnotetext{
* See http://www.textworld.com/scp

** Fillmore (2007), Herbst (2010), and Fellbaum and Baker (2013) identify valency patterns at the lexical level. The Leipzig Valency Classes Project is an extensive typological project comparing and contrasting verbs and valency classes (http://www.eva.mpg.de/lingua/ valency/index.php).
} 
the FrameNet database. We expect to find analogous structures in the collected corpus with more limited variability compared to those in the inventory.

The FrameNet Project illustrates an application of Frame semantics principles to corpus data. It develops a lexical database of English that is both humanand machine-readable, which contains annotated examples of words as they are used in actual texts. It is helpful to both students and researchers. For students it is a dictionary of more than 13000 word senses, most of them annotated to show the meaning in context. For researchers in Natural Language Processing, it provides more than 200000 manually annotated sentences linked to more than 1200 semantic frames. It serves as a training dataset for semantic role labeling, applicable in information extraction, machine translation, event recognition, sentiment analysis, etc. For students and teachers of linguistics, it plays the role of a valency dictionary, giving evidence for the English vocabulary's combinatorial properties. The project started in 1997 at the International Computer Science Institute in Berkeley. Databases similar to FrameNet have been built for a number of languages and currently linguists are working on aligning the FrameNets across languages.

In FrameNet, the role names (called frame elements) are common to particular conceptual structures (frames); some of these are quite general, while others are specific to a small family of lexical items. Figure 1 shows some subframes of the TRANSPORTATION frame.

Table 1. A subframe can inherit elements and semantics from its parent (adopted from Baker, Fillmore, Lowe, 1998)

\begin{tabular}{|l|}
\hline frame(TRANSPORTATION) \\
frame_elements(MOVER(S), MEANS, PATH) \\
scene(MOVER(s) mOve along PATH by MEANS) \\
\hline frame(DRIVING) \\
inherit(TRANSPORTATION) \\
frame_elements(DRIVER (=MOVER), VEHICLE \\
(=MEANS), RIDER(s) (=MOVER(s)), CARGO \\
(=MOVER(s))) \\
scenes(DRIVER starts VEHICLE, DRIVER con- \\
trols VEHICLE, DRIVER StOpS VEHICLE) \\
\hline frame(RIDING_1) \\
inherit(TRANSPORTATION) \\
frame_elements(RIDER(S) (=MOVER(S)), VE- \\
HICLE (=MEANS)) \\
scenes(RIDER enters VEHICLE, \\
VEHICLE carries RIDER along PATH, \\
RIDER leaves VEHICLE ) \\
\hline
\end{tabular}

Analogically, we expect the ENTER frame and the GO INTO frame to specify a MOVER, a GOAL, and potentially PATH and/or SOURCE as secondary elements. In this frame, the MOVER initiates and controls the movement. For most verbs in this frame, the MOVER is realized as a subject; the GOAL can appear as a direct object; and PATH and SOURCE can be oblique complements. 
Each frame should have some core elements and optionally some non-core/ peripheral elements, which can be interpreted as semantic roles, and possibly extrathematic elements.

The core elements are always overtly specified and realized by a core syntactic function (subject, object). Non-core/ peripheral elements, on the other hand, specify time, place, manner, etc. usually associated with situations. Extrathematic elements appear in sentences and evoke other frames, e.g. cause, purpose, reason, etc.

\section{Corpus analysis}

\subsection{Enter}

According to the Oxford Dictionary of English, the verb enter has four main meanings: 1. Come or go into (a place) [with object]; 2. Begin to be involved in; 3. Write or key (information) in a book, computer, etc.; 4. (in Law) Submit (a statement) in an official capacity.

\subsubsection{Enter (Come or go into (a place) [with object])}

Figure 1. FrameNet annotation of enter (meaning 'arriving')*

\section{enter.v}

\begin{tabular}{|l|l|}
\hline \multicolumn{1}{|c|}{ Frame Element } & \multicolumn{1}{c|}{ Core Type } \\
\hline \hline Circumstances & Extra-Thematic \\
\hline \hline Cotheme & Extra-Thematic \\
\hline \hline Degree & Extra-Thematic \\
\hline \hline Depictive & Extra-Thematic \\
\hline \hline Event_description & Extra-Thematic \\
\hline \hline Frequency & Extra-Thematic \\
\hline \hline Goal & Core \\
\hline \hline Manner & Peripheral \\
\hline \hline Means & Peripheral \\
\hline \hline Mode_of transportation & Peripheral \\
\hline \hline New situation & Extra-Thematic \\
\hline \hline Path & Peripheral \\
\hline \hline Period_of_iterations & Extra-Thematic \\
\hline \hline Place & Peripheral \\
\hline \hline Purpose & Extra-Thematic \\
\hline \hline Re-encoding & Extra-Thematic \\
\hline \hline Source & Peripheral \\
\hline \hline Theme & Core \\
\hline \hline Iime & Peripheral \\
\hline \hline
\end{tabular}

\footnotetext{
* Adopted from FrameNet: https://framenet.icsi.berkeley.edu/fndrupal/luIndex.
} 
Due to the specificities of the context we suggest that only the first meaning should be exemplified in the corpus. According to the dictionary data, enter is of second valency as it governs two elements - a subject and an object. In FrameNet's terminology enter is accompanied by two core elements: a Theme (a MOVER) and a Goal. Figure 1 shows the frame elements associated with enter with their matching core types.

Thus, a prototypical example would be

\section{As the plunger moves down, fuel ENTERS the cylinder.}

[Time] [Theme] [Goal]

where both Core elements of Theme ('fuel') and Goal ('the cylinder') are explicitly presented. Along with them, the sentence contains the Peripheral element of Time which is explicitly expressed by means of a subordinate time clause introduced by 'as' and representing a simultaneous event.

However, the analysis of the corpus showed a possibility of enter having a valency of 1 with just one core element - a Theme, with the second core element (the Goal) being implicitly identified by the context. For instance,

2286 The effectiveness of an IGS depends on maintaining a positive pressure in the cargo tanks so that oxygen will not ENTER.

[Theme]

27179 The high-pressure fuel ENTERS and travels down a passage in the body.

[Theme]

In the first example there are no additional Peripheral and Extra-Thematic elements. In the second, 'and travels down a passage in the body' may be considered as an Extra-Thematic element of a new situation.

27045 In each the fresh air ENTERS as the inlet port is opened by the downward [Place] [Theme]

[Time]

movement of the piston.

In example 27045 the Core element of Goal is not mentioned. Instead, there is a Peripheral element of Place - 'in each' and a Peripheral element of Time which is similar to that in example 27129 above.

25201 For instance, a ship with no internal subdivision could operate safely until water ENTERED by some means.

[Theme] [Means]

Similarly to the previous example, the Core element of Goal is not mentioned in 25201 because it can be elicited from the context. The additional Peripheral element is that of Means. It is also possible for the clause governed by the verb enter to appear without a Theme: 
38382 When a closed space has to be ENTERED, there must be a second person in [Goal]

attendance at the entrance...

The Passive voice construction is a typical case where a typically transitive verb such as enter turns into monovalent. As enter is in a subordinate clause here, the Theme is implied in the main clause of the sentence. A similar example is the following, where the Extra-thematic element of Degree is added.

30273 These should be fully ENTERED up to the collar...

[Goal] [Degree]

Still, the excerpts where enter is of second valency are the most common. It is usually accompanied by some Peripheral and Extra-Thematic elements.

27511 Steam ENTERS the turbine with a high energy content... [Theme] [Goal] [Manner]

Apart from the two Core elements there is also a Peripheral element of Manner introduced by with.

27064 With uniflow scavenging the incoming air ENTERS at the lower end [Circumstance] [Theme] [Path]

of the cylinder and leaves at the top.

The additional elements are the Peripheral element of Path represented by an atPP (Prepositional phrase) and the Extra-Thematic element of Manner (with-PP). The Core element of Goal is included in the Path-phrase and 'leaves at the top' is an Extra-Thematic element of a new situation.

$2390 \ldots$...water would tend to ENTER the ship through the hole in the hull. [Theme] [Goal] [Path] [Place]

The above example shows two Core elements, Theme and Goal, and two Peripheral (Path and Place).

47194 The ship is to ENTER port from an anchorage with a maximum draft of $7.6 \mathrm{~m}$. [Theme] [Goal] [Source] [Manner]

Again two Core elements are used and two Peripheral but this time they are Source and Manner. Or there may be a combination of the Peripherals - Mode of transportation and Source as in the following example :

$34460 \ldots$ because of the risk from legionella bacteria entering the respiratory [Theme]

[Goal]

system by way of fine mist from a shower spray

[Mode of transportation] [Source]

28411 In a centrifugal pump liquid ENTERS the centre or eye of the impeller... [Place $] \quad$ [Theme $\quad$ Goal $]$ [Re-encoding] 
The Extra-Thematic element of Re-encoding is realized when the clause contains a synonym of another element in the same clause: the 'eye of the impeller' is an alternative way to call 'the centre' of the same device.

25193 (1) Water entering as a result of damage or human error in not having [Theme] [Reason]

watertight boundaries sealed.

The example above features one Core element (the Theme) and an additional Extra-Thematic element of Reason, not included in FrameNet annotation.

As seen in the examples above, enter when used with its first main meaning of 'come or go into a place' can be analyzed in terms of the Arriving Frame, presupposing two Core elements - a Theme (the Mover) and a Goal towards which the Theme moves. The corpus exhibits frequent omissions of one of the Core elements, which is associated with change in the valence of the verb. Such omissions can be referred to either constructional null instantiations when allowed or required by the particular syntactic pattern employed, or definite null instantiations where the Core element omitted is implied and elicited from the context. The Theme element can be omitted by means of passive constructions and infinitive and gerund subjects, i.e. it is associated with constructional null instantiation, whereas the Goal element, being implied in the verb itself and identified in the context, is subject to definite null instantiation.

\subsubsection{Enter into}

We did not expect the second main meaning of enter 'Begin to be involved in' to be exemplified in the corpus as it usually presupposes animate subjects. Yet, there are a number of instances in the corpus referring to this sense. According to FrameNet, where this meaning is defined as 'activity_start', the following frame elements and core types are linked to enter (see Figure 2): 


\section{enter.v}

\begin{tabular}{||l|l|}
\hline \multicolumn{1}{|c|}{ Frame Element } & \multicolumn{1}{|c|}{ Core Type } \\
\hline \hline Activity & Core \\
\hline \hline Agent & Core \\
\hline \hline Circumstances & Extra-Thematic \\
\hline \hline Co-timed_event & Extra-Thematic \\
\hline \hline Communicative_force & Extra-Thematic \\
\hline \hline Concessive & Extra-Thematic \\
\hline \hline Containing_event & Extra-Thematic \\
\hline \hline Depictive & Extra-Thematic \\
\hline \hline Event_description & Extra-Thematic \\
\hline \hline Explanation & Extra-Thematic \\
\hline \hline Manner & Peripheral \\
\hline \hline Means & Peripheral \\
\hline \hline New_situation & Extra-Thematic \\
\hline \hline Particular_iteration & Extra-Thematic \\
\hline \hline Place & Peripheral \\
\hline \hline Purpose & Peripheral \\
\hline \hline lime & Peripheral \\
\hline \hline
\end{tabular}

Figure 2. FrameNet annotation of enter (meaning 'activity_start')

The corpus displays only four examples of this sense. In most of the cases, enter combines with two core elements - Agent and Activity and a number of Peripherals.

58539 Rolls-Royce has recently ENTERED into a long-term research pact with [Agent] [Activity]

Japan's National Institute for Materials Science (NIMS) to develop high[Purpose]

temperature superalloys for use in gas turbines.

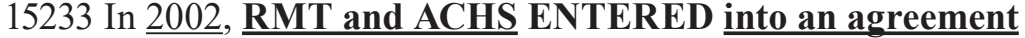 [Time] [Agent] [Activity]}

to develop the landfill gas into the primary energy source for the high school. [Purpose]

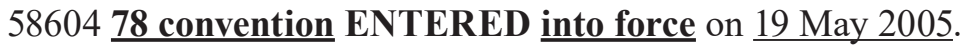
[Agent]
[Activity]
[Time]

The subjects of the above examples are not prototypical agents because they are inanimate. Still, they are metonymically related to animate creatures. 'RollsRoyce' and 'RMT and ACHS' are companies which stand for their managers

\footnotetext{
* Adopted from FrameNet: https://framenet.icsi.berkeley.edu/fndrupal/luIndex.
} 
who are the people signing 'a long-term research pact' or 'an agreement'. 78 convention is a metonymy for the people who have adopted it and are going to abide by it.

The Core element of Activity is not prototypical either as the preposition into is followed by a NP (Noun phrase). However, by endorsing an agreement, contract, pact, convention, etc., we approve of certain requirements that have to be met and particular activities which need to be performed. A Part-Whole metonymical relation exists between a document and the text included in the same document. Additionally, the Peripheral elements of Time and Purpose are used to provide further information.

In one of the cases enter forms a non-finite phrase and combines with just one Core element [Activity], e.g.

30218 Fighting a fire on board ship may amount to a life or death struggle; to ENTER into such a conflict unprepared and unarmed is to invite failure.

[Activity]

Only the Core element of Activity participates in the above Frame, with a constructional null instantiation of the Agent.

Clearly, the small number of instances of enter into does not allow us to study all Peripheral and Extra-Thematic elements exhaustively. But it is evident that 'Begin to be involved in' is not a common meaning in a technical context.

\subsection{Go into}

The Oxford Dictionary of English identifies the following meanings of go into: 1 . (position) to fit in sth, to be able to be contained in sth; 2. (vehicle) to hit/make a violent contact with sth; 3 . to join an organization, to enter sth; 4 . (vehicle/driver) to start the specified movement; 5 . to begin to act or behave in the specified way; 6. to examine/investigate sth carefully; 7. (resources, time, etc.) to be spent on sth or used to do sth. Due to the specificities of the respective context, we can assume that the limited occurrences of go into in the corpus are associated primarily with meanings 1 and 5 above, which can be related to the Motion, Traversing, Arriving Frame and the Activity - Start Frame of FrameNet.

FrameNet does not provide a separate list of frames associated with phrasal verbs. Hence, we are going to construct a table of Frame elements and Core types concerning go into, although the number of examples is limited.

\subsubsection{Go into - 'Begin to act or behave in the specified way'}


As the meaning of go into in this case is associated with the Frame of Activitystart, we can expect the same frame elements to be presented, with a Theme and an Activity as Core ones.

12408...the compressor can GO INTO surge in less than 50 milliseconds [...] [Agent] [Activity] [Time]

the power turbine can GO INTO overspeed in less than two seconds.
[Agent]
[Activity]
[Time]

12210 ...the angle of attack increases until the compressor airfoil GOES INTO stall. [Agent]

[Activity]

12195 This phenomenon occurs at certain conditions of airflow, pressure ratio, and speed (rpm), which result in the individual compressor airfoils GOING INTO

$$
\text { [Agent] }
$$

stall similar to that experienced by an airplane wing at a high angle of attack. [Activity]

Thus, based on the examples included in the corpus, the following table can be drawn:

Table 2. Annotation of go into (meaning 'Activity_start')

go into.v

\begin{tabular}{|c|c|}
\hline Frame Element & Core Type \\
\hline Activity & Core \\
\hline Agent & Core \\
\hline Time & Peripheral \\
\hline
\end{tabular}

Due to the specific characteristics of the context, not all frame elements associated with the frame 'Activity_start' are presented here. The negative connotation of the Activity represented by a NP in the examples above excludes the possibility of expressing Purpose as a Peripheral Element. In addition, similarly to the case of enter meaning 'Activity_start', the Agents do not exhibit the features of the prototypical agent, i.e. they are inanimate and cannot be considered as metonymically standing for animate entities involved.

\subsubsection{Go (into) - 'motion'}

Despite the expectation that the verb go will appear in technical texts in its main meaning associated with Motion and can be analysed in terms of the Motion Frame, the corpus contains only one occurrence of the verb with this meaning:

23383 The ship may GO INTO areas not originally planned.

[Theme]

[Goal] 
FrameNet identifies seven possible Core elements (Area, Direction, Distance, Goal, Path, Source and Theme) which may be explicitly presented in a sentence, accompanied by a number of Peripheral and Extra-Thematic elements (Figure 3)

Figure 3. FrameNet annotation of go (meaning 'motion')*

\begin{tabular}{|c|c|}
\hline \multicolumn{2}{|}{$\mathbf{g o . V}$} \\
\hline Frame Element & Core Type \\
\hline Area & Core \\
\hline Carrier & Extra-Thematic \\
\hline Containing_event & Extra-Thematic \\
\hline Degree & Extra-Thematic \\
\hline Depictive & Extra-Thematic \\
\hline Direction & Core \\
\hline Distance & Core \\
\hline Duration & Peripheral \\
\hline Frequency & Extra-Thematic \\
\hline Goal & Core \\
\hline Iterations & Extra-Thematic \\
\hline Manner & Peripheral \\
\hline Path & Core \\
\hline Path_shape & Extra-Thematic \\
\hline Place & Peripheral \\
\hline Purpose & Extra-Thematic \\
\hline Result & Extra-Thematic \\
\hline Source & Core \\
\hline Speed & Peripheral \\
\hline Theme & Core \\
\hline Time & Peripheral \\
\hline
\end{tabular}

Example 23383 above illustrates the use of two Core Elements - a Theme and a Goal. No additional Peripheral or Extra-Thematic Elements are included in the sentence.

\subsubsection{Go (into) - 'Fluidic motion'}

The following sentence can be considered as belonging to the Frame of Fluidic Motion, the specific Frame elements for the prototypical verb of fluidic motion (flow) being listed in Figure 4 below.

22536 Damping is also felt because of the energy that GOES INTO the wave system created by the ship. ['Fluid']

[Goal]

* Adopted from FrameNet https://framenet.icsi.berkeley.edu/fndrupal/luIndex 
Figure 4. FrameNet annotation of flow (meaning 'fluidic motion')*

\section{flow.v}

\begin{tabular}{|c|c|}
\hline Frame Element & Core Type \\
\hline Area & Core \\
\hline Configuration & Extra-Thematic \\
\hline Depictive & Extra-Thematic \\
\hline Distance & Peripheral \\
\hline Duration & Peripheral \\
\hline Explanation & Extra-Thematic \\
\hline Fluid & Core \\
\hline Goal & Core \\
\hline Manner & Peripheral \\
\hline Path & Core \\
\hline Place & Peripheral \\
\hline Result & Extra-Thematic \\
\hline Source & Core \\
\hline Speed & Peripheral \\
\hline Time & Peripheral \\
\hline
\end{tabular}

We can justify the application of the Fluid_Motion Frame to the analysis of example 22536 by comparing it to the following example provided in the FrameNet annotation:

The ancient Chinese believed that the electrical energy of the body FLOWED in ['Fluid']

specific channels known as the acupuncture meridians, and charts illustrating [Area]

these have been known for several thousands of years.**

In the particular examples, flow and go into express a similar meaning related to energy flowing in an area or to a goal. In both sentences, the subject or the entity which performs the fluidic motion is not prototypical in that it is not a substance (following The Oxford Dictionary of English, fluid is 'A substance that has no fixed shape and yields easily to external pressure; a gas or (especially) a liquid'). Thus, the examples illustrate the use of two Core Elements - a 'Fluid' and a Goal/Area.

\subsubsection{Go into - 'To be spent on sth or used to do sth'}

The analyzed corpus includes two occurrences of go into associated with the Frame of Using_Resource identified in FrameNet:

20903 Of course, that's not going to happen and although a wealth of R\&D HAS

\footnotetext{
* Adopted from FrameNet https://framenet.icsi.berkeley.edu/fndrupal/luIndex

** Adopted from FrameNet https://framenet.icsi.berkeley.edu/fndrupal/luIndex
} 
[Portion] [Resource]

GONE INTO creating KM System Technology, integration of shipboard [Purpose]

sub-systems supplied by different manufacturers is still a large market and a challenge to overcome for technical companies and electronics suppliers.

23859 Apart from tests of individual models a great deal of work HAS GONE [Portion] [Resource]

INTO ascertaining the influence of hull form on resistance.

[Purpose]

Since FrameNet does not provide a specific lexical annotation of go into, we will use the one suggested for spend to base our analysis on.

Figure 5. FrameNet annotation of spend (meaning 'using resource')*

spend.v

\begin{tabular}{|c|c|}
\hline Frame Element & Core Type \\
\hline Agent & Core \\
\hline Manner & Peripheral \\
\hline Means & Core \\
\hline Place & Peripheral \\
\hline Portion & Core \\
\hline Purpose & Core \\
\hline Resource & Core \\
\hline Time & Peripheral \\
\hline
\end{tabular}

As seen in Figure 5, the Frame of Using_Resource is characterized by five Core Elements (Agent, Means, Portion, Purpose and Resource). Due to the different syntactic pattern of go into, which can be considered as corresponding to the passive construction of using spend in the analogous sense, the explicit expression of the Agent is excluded from the possible Frame elements for go into. Therefore, the Core elements of the Frame of Using_Resource employing go into as predicate will be Means, Portion, Purpose and Resource (Figure 6).

Figure 6. Annotation of go into (meaning 'using resource')

go into.v

\begin{tabular}{|c|c|}
\hline Frame Element & Core Type \\
\hline Manner & Peripheral \\
\hline Means & Core \\
\hline Place & Peripheral \\
\hline Portion & Core \\
\hline
\end{tabular}

* Adopted from FrameNet https://framenet.icsi.berkeley.edu/fndrupal/luIndex 


\begin{tabular}{|c|c|}
\hline Purpose & Core \\
\hline Resource & Core \\
\hline Time & Peripheral \\
\hline
\end{tabular}

Our examples (sentences 20903 and 23859) display the use of three Core elements, i.e. Portion, Resource and Purpose, with no additional Peripheral or Extra-Thematic elements involved. Although implicitly understood in the context, agency is not and cannot be explicitly expressed and the subjects are non-prototypical and inanimate, meaning 'resource'.

\subsubsection{Go into - 'Examine/investigate sth carefully'}

The last example of go into in the corpus is related to the Research Frame of FrameNet and uses only one Core element - Topic:

25079 It is not possible to GO INTO the theory of noise generation and [Field]

transmission in a book such as this but the reader should be aware of the general [Place] factors involved.

The FrameNet annotation of the prototypical verb used in the Research Frame (research) identifies the Core elements of Question, Researcher, Topic and Field, the Peripheral elements of Manner, Means, Place, Purpose and Time, and the Extra-Thematic elements of Duration, Population and Type. As the verbs research and go into are synonyms in this particular sense of 'examine/ investigate sth carefully' and are both related to the Research Frame, we can assume that the same Frame elements can be employed in the annotation of go into (meaning 'examine/investigate sth carefully') (Figure 7). Out of the Frame elements listed in FrameNet, the example above displays the use of only one Core element - the Element of Field and the Peripheral element of Place. The Core element of Researcher is subjected to Constructional Null Instantiation and is understood in the context as referring to the authors.

Figure 7. FrameNet annotation of go into (meaning 'examine/investigate sth carefully')*

go into.v

\begin{tabular}{|c|c|}
\hline Frame Element & Core Type \\
\hline Duration_of_state & Extra-Thematic \\
\hline Field & Core-Unexpressed \\
\hline Manner & Peripheral \\
\hline Means & Peripheral \\
\hline Place & Peripheral \\
\hline
\end{tabular}

* Adopted from FrameNet https://framenet.icsi.berkeley.edu/fndrupal/luIndex 


\begin{tabular}{|c|c|}
\hline Population & Extra-Thematic \\
\hline Purpose & Peripheral \\
\hline Question & Core \\
\hline Researcher & Core \\
\hline Time & Peripheral \\
\hline Topic & Core \\
\hline Type & Extra-Thematic \\
\hline
\end{tabular}

The corpus clearly indicates a limited use of the verb go in the technical context in terms of frequency of occurrence and range of meanings. Moreover, it is not the lexical form predominantly used to represent physical motion, although this is the main meaning of the verb which accounts for its frequent occurrence in general English.

\section{Conclusion}

To sum up, the article presents a study based on a corpus of texts in the field of marine engineering, naval architecture and ship handling including specialized textbooks and magazine articles. The objective is to identify and analyze the different frames in which enter and go into occur and to define the contextspecific frame elements surrounding them in their various uses. The results of the corpus data analysis suggest that there is a heavy asymmetry in the use of the two verbs investigated, with a significant predominance of enter in the cases where the meaning of 'arriving' is realized and a very limited number of the instances representing initiation of an activity ('Activity_Start'). In addition, the latter are not prototypical examples of predications belonging to the 'Activity_Start' Frame and feature non-prototypical assignments for both the Agent and the Activity Frame elements. On the other hand, the verb go, and particularly go into, which was chosen as it is contextually synonymous to enter and extremely frequent in the general English context, exhibits even greater limitations in terms of frequency of occurrence and variety of senses and patterns. The analysis results definitely indicate that enter is the preferred lexical form when the use of the two lexical forms is possible. The corpus data also suggest the use of go into in the 'Activity_Start' Frame with a negative connotation of the Activity element.

Frame semantics has been used here to provide accounts of a variety of lexical, syntactic, and semantic phenomena. The Frame semantics approach employed in the present study may be applied to the analysis of other motion verbs in the specialized context in order to identify the frames which they take part in and the frame elements surrounding them. Moreover, other areas such as first language acquisition, foreign language learning and teaching, as well as diachronic studies might also employ and benefit from the Frame semantics approach. 


\section{References:}

Alan, K. (2001). Natural language semantics. Oxford: Blackwell Publishers Ltd.

Baker, C. F., Fillmore, C., \& Lowe, J. B. (1998). The Berkeley FrameNet project. Proceedings of ACL-COLING, 86-90.

Evans, V. (2006). Lexical concepts, cognitive models and meaning-construction. Cognitive Linguistics, 17(4), 491-534.

Fellbaum, Ch., (Ed.). (1998). WordNet: An electronic lexical database, language, speech, and communication series. Cambridge MA: The MIT Press.

Fellbaum, Ch., \& Baker, C. (2013). Representing verb meaning in complementary resources. Linguistics, 54(1), 707-728.

Fillmore, C. (1977). Scenes-and-frames semantics. In A. Zambolli (Ed.), Linguistic Structure Processing (pp. 55-82). Amsterdam: North Holland Publishing Company.

Fillmore, C. (1982). Frame semantics. In Linguistic Society of Korea (Ed.), Linguistics in the Morning Calm (pp. 111-38). Seoul: Hanshin.

Fillmore, C. (2006). Frame semantics. In D. Geeraerts (Ed.) Cognitive linguistics: Basic readings (pp. 371-400). Berlin/New York: Mouton de Gruyter.

Fillmore, C. (2007). Valency issues in FrameNet. In T. Herbst, \& K. Götz-Votteler (Eds.), Valency: Theoretical, descriptive and cognitive issues (pp. 129-160). New York: Mouton de Gruyter.

Fillmore, C. J., Atkins, B. T. S. (1992). Toward a frame-based lexicon: The semantics of RISK and its neighbors. In A. Lehrer, \& E. Kittay (Eds.), Frames, fields and contrasts: New essays in semantic and lexical organization (pp. 75-102). Hillsdale: Erlbaum.

Fillmore, C. J., Atkins, B .T. S. (1994). Starting where the dictionaries stop: The challenge for computational lexicography. In B. T. S. Atkins, \& A. Zampolli (Eds.), Computational approaches to the lexicon (pp. 349-393). Oxford: Oxford University Press.

Fillmore, C. J., Atkins, B. T. S. (2000). Describing polysemy: The case of 'crawl.' In Y. Ravin, \& C. Leacock (Eds.), Polysemy (pp. 91-110). Oxford: Oxford University Press.

Fillmore, C., \& Baker, C. (2000). FrameNet web site. Retrieved from http://www.icsi. berkeley.edu/framenet.

Goffman, E. (1974). Frame analysis: An easy on the organization of experience. Cambridge, MA: Harvard University Press.

Goldberg, A. (2010). Verbs, constructions and semantic frames. In M. Rappaport Hovav, E. Doron, \& I. Sichel (Eds.), Syntax, lexical semantics and event structure (pp. 39-58). Oxford: Oxford University Press.

Herbst et al., (Eds). (2004). A valency dictionary of English: A corpus-based analysis of the complementation patterns of english verbs, nouns, and adjectives. Berlin and New York: Mouton de Gruyter.

Herbst, Th. (2010). English linguistics. A coursebook for students of English. Berlin and New York: Mouton de Gruyter.

Oxford Dictionary of English. Retrieved from https://en.oxforddictionaries.com.

Ruppenhofer, J., Ellsworth, M., Petruck, M. R. L., \& Johnson, Ch. R. (2005). FrameNet: Theory and practice. Retrieved from http://framenet.icsi.berkeley.edu. 